\title{
Research on the Novel Education Pattern of College Students Competition based on Cultivating Innovative Talents
}

\author{
Bian Wei \\ Academic affaires office \\ Xijing University \\ Xi'an, China \\ e-mail: 21443022@qq.com \\ * Corresponding Author
}

\author{
Huang Wenzhun * \\ Department of Electronic Information Engineering \\ Xijing University \\ Xi'an, China \\ e-mail: huangwenzhun@xijing.edu.cn
}

\begin{abstract}
In this paper, we research on the novel pattern of the competition based college education mode as based on cultivating innovative talents and teaching reform thought. Competition is based on professional course for university students of science and technology let the students to use the professional knowledge and the extracurricular practice experience to solve the problem of one aspect and to carry out the academic competition. It has a strong comprehensive competition subject, will apply on behalf of the discipline of academic frontier among them, the higher requirements to the participating students. In such a race at the same time, students are required to have learned the professional theory knowledge, but also expand to study. Competition of science and technology is a systematic project, need long time to maintain, and through the accumulation of experience, in the training objectives of the university as the guidance, build events are divided into positive to promote the competition routinization institutionalization and constantly cultivating the student innovative practice ability in order to explore the sustainable development of the road. Our research proposes the new paradigm for the education reform.
\end{abstract}

Keywords-College Education; Teaching Reform; Novel Pattern; Innovation; Competition; Interactive Learning; Independent Thinking; Novel Methodology.

\section{INTRODUCTION}

Innovation is the soul of a nation, is the inexhaustible driving force for the prosperity of a country, innovation is the fundamental education, independent colleges run by the local undergraduate course is an important part of our country's higher education diversification, the aiming at training innovative applied talents and competition of science and technology is a part of the teaching activities, at the same time meet the requirements of private colleges high-level connotative of the general development, reflects the comprehensive strength of the private colleges and the universities teaching, scientific research level, but also run by the local college students show their theory knowledge, innovation ability and comprehensive quality of platform, but also private colleges cultivate one of the important means of applying a comprehensive talent.

To carry out the activities of science and technology is an important way to motivate student innovation ability. Innovation ability is based on the theory of professional knowledge on the exploration and practice of a kind of comprehensive qualities, is a process to put theory into practice. Science and technology competition is outside of the classroom teaching of colleges and universities have close relationship with course of all kinds of competition of science and technology, the integrated use of the interdisciplinary knowledge to design and to solve the problem. Competition of science and technology activity is generally conducted in laboratory and the atmosphere was active, and not constrained by fixed form of the classroom teaching. In guiding teacher, select all kinds of innovative experimental project, illuminating competition activities, topic selection analysis, design production commissioning, complete works until the thesis writing and a series of the process, guide and help students to establish the innovation idea, cultivate practical skills, independent thinking, to solve practical problems, divergent to develop innovative thinking and the logic thinking to improve the students comprehensive quality.

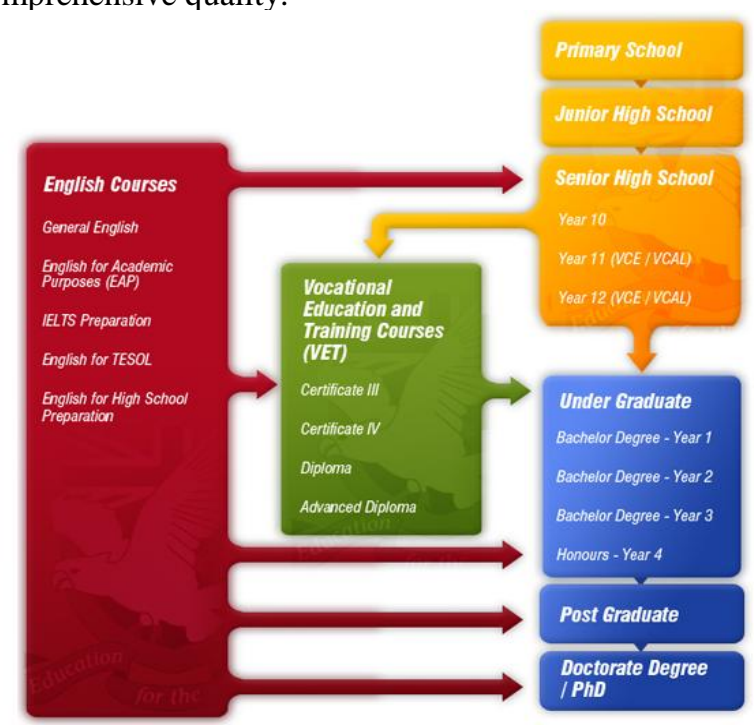

Figure 1. The Demonstration of the Modern Education System

As demonstrated in the figure one, we illustrate the construction of the modern education system. Science and technology is the first productive force, and as the most important factors in the engineering and technology is the first productive force. Engineer is to develop and master the core technology, with the technology innovation to 
promote the development of national industry leader. As an important part of the innovation ability, engineering quality and innovation spirit is a quality requisite to engineer, at the same time it is also the key points in the engineering training center functions. Engineering training, therefore, should be to cultivate the students' engineering quality and innovation spirit as the main target, and the starting point to design and the specific operation of the engineering training center training method. Starting from the connotation of the engineering quality and innovation spirit, namely from cultivation of engineering knowledge, engineering consciousness and practice ability, from cultivating innovation consciousness innovation action.

In this paper, we research on the novel pattern of the competition based college education mode as based on cultivate innovative talents and teaching reform thought. The current university on the innovative talent training at the exploration stage has not yet formed a mature mode or a certain paradigm, so there is no experience to talk about, only in the logic of innovation talents training. The basic logic of cultivating the creative personnel should be the combination of the humanistic education and professional education. Professional education is education talent, to the humanities education is adult education, the two together constitute basic content of cultivating creative personnel. Innovative talent training requires teachers to their own innovation consciousness, innovation spirit and innovation and practical action, when students confused without lead, have a humbug out and confused. Teachers must update teaching ideas, and always to cultivate student exploration spirit, comprehensive ability and innovation consciousness and innovation ability as teaching aims, respect students and establishment of a democratic and equal relationship between teachers and student developing creative teaching activities, create democratic, loose discussion atmosphere, causes the student in good teaching atmosphere, learning from each other, bold communication to improve together.

\section{The Proposed Methodology}

\section{A. The College Students' Training Mode}

Personnel training mode fundamentally defines the characteristics of the talent reflect the education thought and the education idea and focus. To cultivate high quality applied talents, colleges and universities need to bold break through the conventional understanding of personnel training mode, grasp the core element of the talent training and links. University student employment contradiction is caused by many of factors is not an isolated problem. In addition, the poor students' own quality and employment consciousness and so on is also important.

Theoretically, the current situation of college students' innovation ability could be summarized as the follows. (1) Constancy of creative thinking is relative to the practice in terms of thinking, refers to the relationship between things to unprecedented thinking, thereby creating something new way of thinking is the sum of all form of thinking with the new content. Innovative thinking is not only the basis of innovative consciousness and innovative ability, is the core of cultivating innovative talents. Creative thinking is the most important factors in the positive and opposite, but our country's university students at an early age to accept a passive study way with the stress on memory, logical rigor, continuity and the cultivation of no of the contradiction. Over time, students have developed kind of trying to make their own mindset, general lack of imagination, criticism and questioning mind ability, and then show the innovative thinking ability is poor. (2) In our country, under the traditional education concept of students' general learning performance appraisal is the main standard of the emphasis on memorization and representation of knowledge, has not put into the assessment standard of students' innovation ability. As a result, students' innovation power shortage, most college students think their own lack of innovation and the innovation consciousness. (3) Innovation ability mainly includes the main body of information gathering and processing ability, the choice of target ability, practical ability and expressing ability and materialized. In Chinese traditional education has been emphasized by teachers to impart information and knowledge is given priority to, contempt for students independence, initiative to collect and the process information ability with weak information gathering and processing ability of college students. Main show is not effectively use all kinds of modern methods to improve efficiency of information collection, information processing is often limited to simple pile and combination, utilization rate is not high, the lack of creativity.

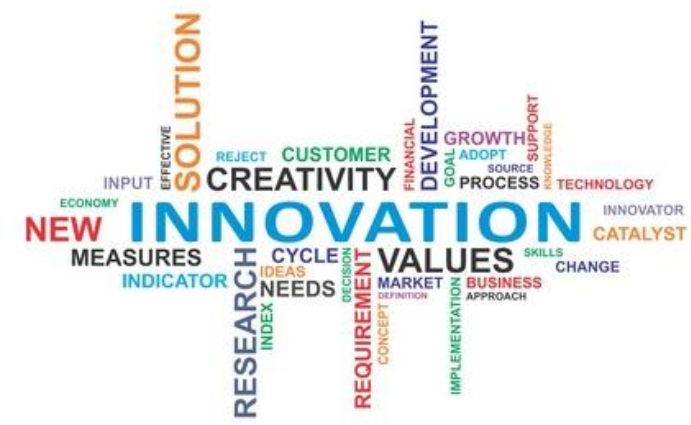

Figure 2. The Keywords of the Innovation

As demonstrated above, the keyword of the innovation is shown. At present, more and more students intern of unit of choose and employ persons is regarded as an important source of its human resources. If destination is in the student internship training students' ability of the related aspects, once the students graduation to work and we can immediately take positions, to shorten the student to unit of choose and employ person novitiate. Effect the quality of the practice not only with the students' practical ability, the ability to solve the problem such as the cultivation of the comprehensive quality has a direct relationship, but also directly affect the practice base for students and schools, thus influence its priority when recruiting the new staff whether the school graduates. So, practice better able to create more of the employment opportunities, employment in turn promoting the improvement of the internship effect.

Build with ability as the goal of practice teaching system. Practice teaching is the main carrier of cultivating students' practical and the application ability, therefore, the colleges and universities in addition to the proportion of the practice teaching link credits given basic requirements, should also focus on building ability as the goal of practice teaching system, and the ability training students learning throughout the whole process. 
Practice ability as the core of the academic evaluation. Academic assessment is the reversed transmission and the important way to promote teaching reform of education. In order to cultivate the students' practical ability to innovate, colleges and universities should actively promote the reform of ability as the core of the academic evaluation approach as adhere to the combination of knowledge and ability of examination, combining the result evaluation and process evaluation, assessment of students' application ability and practice ability. Curriculum reform to advance in form of project appraisal way and shall be formulated by the relevant departments to reform the process.

\section{B. The Educational Reform in Colleges}

In order to meet the need of economic and the social development of talents, colleges and the universities in the course of experiment teaching reform, the purpose is to improve the quality of experiment teaching and the teaching effect, improve the quality of personnel training, for training and fostering students' innovation ability and practice ability to provide a reliable guarantee. At present, a series of experiment teaching reform in colleges and universities is not plain sailing. In the works, often face some of the specific practical problems, to be effectively implemented, need society, school, teacher, student and so on various aspects of close cooperation and support, and in the process of reform, each work link to a ring by ring, to keep the consistency and continuity of each other, before and after the realization of the experimental teaching reform to the road to success.

In the era of knowledge economy, the social demand for talent is witnessing profound changes, pays attention to the coordinated development, to develop the knowledge, ability and quality designed combination of a liberal, is each college consensus on talent training mode reform, also is the world trend of talent training mode reform. This is not only the deepening understanding of the education thought, is closer to the nature of the education conceptual change, is adapt to necessity of higher education reform and development in the new period. Therefore, the reform of traditional personnel training mode in university, to construct our social economic, political, and cultural needs of the new personnel training mode is the inevitable choice of history. The context of education reform of higher education is to cultivate social professionals mission, is also responsible for cultivating the talents of the all-round development of the humanities education mission.

In the new era of international competition is the competition between talents, but also the competition between the humanities. On the occasion of the further reform and development, to realize the revival of nation, China not only requires rapid economic development, science and technology, also contains the profound cultural accumulation. Curriculum group construction is based on the cultivation of the students as the main line, as a link to a logical connection with course, supported by teachers' team, with quality benefit as the gripper, deepen teaching reform as the power of a new mode of course construction.

The reform should follow the listed suggestions. (1) Reform of the curriculum group system, coordinate the relationship between the courses in the same group, reduce duplication of content, on the whole, the teaching contents from difficult to easy and according to the logical structure of sequence, analyses the basis and practice the scientific systematic curriculum structure, teaching content and the goal of start time sequence. Curriculum group of system should be composed of required courses, elective courses and experiment, the proportion of practical courses by the suitable for together. (2) Teaching team construction is the current colleges and the universities to improve teachers' quality and the most important ways of education teaching level based on the curriculum group construction, team construction of the teaching innovation. (3) On school distribution, appropriate adjustment with the theory school proportion between the basic courses and the experimental courses, learning content unchanged on the basis of the basic theory of the guarantee, increase practical application class hours. Form a group of new undergraduate training program, teaching outline and the experiment outline. (4) In view of the comprehensive course group of constitute, for the test methods need to explore a variety of ways, comprehensive assessment of students' understanding of the learning content and actual performance.

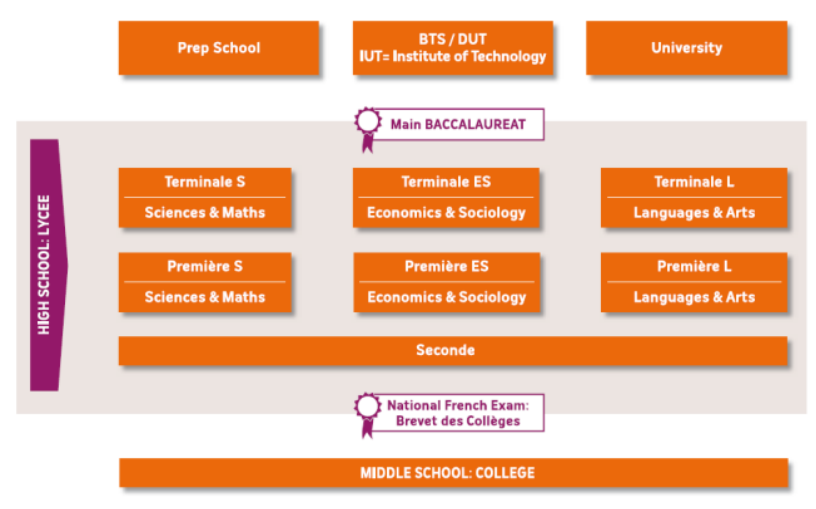

Figure 3. The Curriculum System in Colleges

\section{The Innovative Personnel Training}

The cultivation model of creative talents training mode is one of paradigm. Personnel training mode is to point to in the certain education thought and education under the guidance of the theory, in the education system and plan for the realization of the training objectives, formed in the teaching practice of a certain style and characteristics of organization pattern and operation mode.

Training target is peculiar to the colleges and the universities cultivate human species level, specifications and requirements. It is the state's overall education target embodiment in the field of higher education, it is not only the concrete embodiment of the university concept, is a kind of what will be the university idea and planning, what is the goal, will produce what kind of person, and it is related to strategic issues in the educational reform and the development. Personnel training mode is adapted to the local economy was the product of social development objective request, once the economic and the core social transformation, the original pattern inevitably exist not the adaptability, the need for the change. So, the personnel training mode and show the dynamic characteristics.

Personnel training mode is constrained by a series of interconnected, orderly system consisting of a number of elements. These factors include: training target, teaching methods, teaching form, the course system and teaching 
of operational mechanism and so on. The talent training mode of study must be combined with the specific school practice and specific professional and the internal and external environment. Innovative talents cultivation model demands for innovation education idea, the innovation as the goal, to cultivate talents by the developing effective innovative talent training plan and put into practice, so as to form a unique style and characteristics of innovative talents training mechanism. By the course design, professional design and the project teaching, curriculum experiment, comprehensive experiment teaching units. In experimental teaching, strengthen design, comprehensive experiments; In the teaching of the course project, clear and project related knowledge teaching categories selected topic or theme, it can also be put forward by students', students form the project team, collaboration, project task together in extracurricular, the teacher in class time, introduced by project team selected topic contents, working train of thought, between students to carry out the discussion, teachers to guide and comment, before the end of course, the answer to the project and evaluation.

Through a series of curriculum practice, the teaching theory and the practice together, strengthen the students' subjectivity and the autonomy learning, training students' team cooperation spirit to improve the students' ability to analyze and solve practical problems. To strengthen the construction of the campus practice base and external cooperative education base construction. In the school practice base construction, according to the enterprise's production process, technology and requirements, which meets the practical field, the technological process of the laboratory, in the teaching to the student to carry out the system of skills training, job experience and work ability; At the same time actively carry out cooperative education, the establishment of off-campus practice teaching base, enterprise specialized practice provides guarantee.

In summary, we should follow the listed guidelines. (1) Cultivating high-quality innovative talents, both must insist on improving the comprehensive quality of college students, and should pay attention to students' individual character development as it is helpful to cultivate students' innovative spirit and creative ability. People's body and mind are individual differences, ignore and deny the difference, according to the mode of a single and unified norm fosters the talent, does not conform to the law of higher education. So we must create good conditions and atmosphere for college student personality development, through the establishment of encouraging students to the independent development of the system, to build the cradle of cultivating creative people to provide the good environment, make it onto the regularization and the standardization of orbit. (2) Set up the flexible teaching training system. Credit-system, cancel the make-up exam system failing grades and they'll allow students to drop out of school and graduate ahead of schedule, sharing the essay, excellent students to study a minor in, passed minor graduation certificate. A double major outstanding student to learn this professional or take other professional at the same time and passed the dual diploma.

\section{CONCLUSION AND SUMMARY}

In this paper, we research on the novel pattern of the competition based college education mode as based on cultivate innovative talents and teaching reform thought. Cultivate and improve college students' innovative practice ability, is the subject of current colleges and universities to explore, is the direction of the higher education teaching reform. Competition of science and technology, as an important platform to improve student innovative practice ability, to guide and inspire students to set up innovation concept, improve the analysis of the practical ability to solve the problem. To further perfect the system of the science and technology competition pattern, explore new ability training mode, to improve college students' science and technology innovation ability is of great significance.

\section{ACKNOWLEDGMENT}

This research was financially supported by the 2015 Research Project of Higher Education Reform in Shaanxi (15BY126).

\section{REFERENCES}

[1] O'Day, Jennifer A., Catherine S. Bitter, and Louis M. Gomez, "Education Reform in New York City: Ambitious Change in the Nation's Most Complex School System," Harvard Education Press. 8 Story Street First Floor, Cambridge, MA 02138, 2011.

[2] Qin, Peng, Ying Hua Wang, and Zhi Hai Qin, "A Preliminary Study of the Reform of Water Conservancy Hydroelectric Engineering Major in Education and Course," In Advanced Materials Research, vol. 461, pp. 71-74. 2012.

[3] Edwards, Joan Elaine, "The lived experience of Indonesian nursing faculty participating in a nursing education reform based on the 2009 World Health Organization Global Standards," PhD diss., The University of Texas at Tyler, 2012.

[4] Evans, Leanne Mary, "The Preservation of Effective Instructional Practices in an Era of Education Reform: The Experiences of Exemplary Teachers of English Language Learners," 2012.

[5] Guernsey, Lisa. "Technology in Early Education: Building Platforms for Connections and Content That Strengthen Families and Promote Success in School. The Progress of Education Reform. Volume 13, Number 4." Education Commission of the States (NJ3) (2012).

[6] Malone, Karen, and Salinder Supri, "A critical time for medical education: the perils of competence-based reform of the curriculum," Advances in health sciences education 17, no. 2, pp. 241-246, 2012.

[7] Gershberg, Alec Ian, Pablo Alberto González, and Ben Meade "Understanding and improving accountability in education: A conceptual framework and guideposts from three decentralization reform experiences in Latin America," World Development 40, no. 5, pp. 1024-1041, 2012.

[8] Min, Zhao, "Problems and Improvements Teacher Quality of Private Schools - on the Policy Opportunity of National Medium and Long-Term Education Reform and Development Plan Outline (2010-2020)," Theory and Practice of Education 32, no. 10, pp. 23 $28,2012$.

[9] YU, Hong-liang, and Shi-dong YIN, "Construction of Teachers' Cultivation Pattern-Based on the Practice and Exploration of Teachers' Education Reform in Fuyang Teachers' College," Journal of Fuyang Teachers College (Social Science Edition), vol. 1, 035 2011.

[10] Boone, William J., J. Scott Townsend, and John Staver, "Using Rasch theory to guide the practice of survey development and survey data analysis in science education and to inform science reform efforts: An exemplar utilizing STEBI self - efficacy data," Science Education 95, no. 2, pp. 258-280, 2011. 
[11] CHEN, Da-peng, and Er-kang SUN, "Opening Teaching Iaboratories Raising Innovation Ability of students," Laboratory Research and Exploration, vol. 2, 005, 2001.

[12] LIU, Hedong, and Dongli LIANG, "The Cointegration Analysis between the R\&D Input and the Independent Innovation Ability," Science of Science and Management of S. \& T, vol. 8, 005, 2006.
[13] QIU, Run-he, Jian-an FANG, Ming-hao TANG, Qing-biao WU, and Jian WANG, "Building up an Integrated Experimental Platform and Cultivating Students' Innovation Ability," Research and Exploration in Laboratory, vol. 2, 002, 2006. 